\title{
Using photo-elicitation to explore the lived experience of informal caregivers of individuals living with dementia
}

\author{
Georgie Rayment ${ }^{1}$, Katherine Swainston ${ }^{2}$ and Gemma Wilson ${ }^{3 *}$ (D) \\ 'West Lothian Psychological Approach Team for Dementia (WeLPAT), St John's \\ hospital, NHS Lothian, Edinburgh, UK \\ ${ }^{2}$ School of Social Sciences, Business and Law, Teesside University, Middlesbrough, UK \\ ${ }^{3}$ Department of Nursing, Midwifery and Health, Faculty of Health and Life Sciences, \\ Northumbria University, Newcastle-upon-Tyne, UK
}

Objectives. This study aims to explore the subjective lived experience of informal caregivers supporting an individual with dementia.

Design. This study uses the interpretive phenomenological approach utilizing the method of photo-elicitation and in-depth semi-structured interviews.

Methods. Six individuals were given a disposable camera to capture photographs which they felt illustrated their own lived experiences of being a caregiver of an individual living with dementia. Photographs were printed and used to form discussion within an in-depth semi-structured interview. The photographs provided an innovative way of capturing the lived experiences of formal dementia caregivers and allowed the interview data to be grounded in their daily living, centring around their own lived experiences.

Results. Three themes emerged from data analysis: 'conceptualising the role of informal caregiver', 'support for the informal caregiver', and 'the caregivers own needs'.

Conclusions. Findings demonstrated the complexity of the relationship between the caregiver and the person living with dementia, and the shift in this relationship specifically due to the role of carer, with notable differences between spousal caregivers and adultchild caregivers. The importance of social, emotional, and practical support for caregivers was highlighted, as well as significance of the caregiver's individual needs.

\section{Statement of contribution}

What is already known on this subject?

- Informal caregivers of individuals living with dementia cover much of the associated health care costs.

- Informal caregiving of individuals living with dementia can lead to negative health outcomes of the carer.

- Health outcomes of informal caregivers living with dementia are grounded in culture and are influenced by multiple factors.

What does this study add?

- The complexity of the transition from family member to informal caregiver has both a physical and emotional impact on caregivers.

*Correspondence should be addressed to Gemma Wilson, Northumbria University, Faculty of Health and Life Sciences, Department of Nursing, Midwifery and Health, Coach Lane Campus, Newcastle-upon-Tyne NE7 7XA, UK (email: gemma.wilson@northumbria.ac.uk). 
- The transition, and experiences of informal caregiving, is dependent on the relationship to the individual living with dementia.

- Caregiver support and recognizing the caregiver's individual needs were imperative to caregiver well-being.

Dementia is defined as the deterioration of cognitive function beyond that which is expected (World Health Organisation, 2017). It is estimated that 850,000 people are living with dementia in the United Kingdom, and this figure is expected to increase to one million by 2025 (Alzheimer's Society, 2014). Furthermore, it is proposed that the total health and social care costs for dementia almost match the combined costs of cancer, heart disease, and stroke (Alzheimer's Disease International, 2014). Despite the large health care costs associated with dementia care, those living with dementia, and their families, cover two-thirds of this cost (Alzheimer's Society, 2014).

Informal caregiving is defined as unpaid care provided by a relative or friend (Bremer et al., 2015). However, whilst essential to health and social care provision, it is reported that almost half of caregivers for people living with dementia feel they do not receive the support they need (Alzheimer's Society, 2014), and evidence suggests that over $80 \%$ of informal dementia caregivers experience elevated levels of stress with nearly $50 \%$ reporting that they suffer from depression (Alzheimer's Society, 2014). Caregiver burden is defined as 'a multidimensional response to physical, psychological, emotional, social, and financial stressors associated with the caregiving experience' (Kasuya, Polgar-Bailey, \& Takeuchi, 2000, p. 119). Evidence has shown that caregiving for a relative living with dementia can lead to negative health outcomes for informal caregivers (Bremer et al., 2015), including increased risk of anxiety (Joling et al., 2010) and depression (Mahoney, Regan, Katona, \& Livingston, 2005; Schulz, Boerner, Shear, Zhang, \& Gitlin, 2006), as well as decreased physical well-being and quality of life (Schulz et al., 2006).

The Caregiver Stress Process Model was developed by Pearlin, Mullan, Semple, and Skaff (1990) and brings attention to the various relationships between variables that lead to caregiver stress and the development of these relationships over time. The model constitutes of four domains: background and context, primary and secondary stressors, mediating conditions, and manifestations of stress and provides understanding of how caregiving develops from a reciprocal activity between two people to an unequal distribution of burden (Pearlin et al., 1990). This model argues that caregiver stress is a mixture of circumstances, experiences, reactions, and resources, which impact upon health and behaviour in various ways. This is supported by systematic review evidence which stated that gender, relationship, culture, and personal characteristics all influence carer burden, and is associated with negative effects on health (Etters, Goodall, \& Harrison, 2008). Evidence suggests that caregivers of people living with dementia suffer from higher levels of burden and depression than caregivers of other chronic illnesses (Pinquart \& Sörensen, 2004). Factors including impairment of daily activities, number of hours caregiving, coping strategies, co-residence, spousal status, and gender are all evidenced as predictors of caregiver burden in dementia caregivers (Kim, Chang, Rose, \& Kim, 2012). According to Ayres (2000), this is due to the fact that carers' experiences seem to be vastly different, owing to the nature of dementia and how the caregiver interprets and constructs meaning in their caregiving experience. Furthermore, the perceptions of caregivers for people living with dementia vary considerably (Shim, Barroso, \& Davis, 2012), and it is argued that dementia caregiving 
experiences are grounded in culture (Ivey et al., 2013; Simpson, 2010; Simpson \& Carter, 2010).

Some studies have utilized interpretative phenomenological analysis (IPA) in examining individual differences of caregivers for individuals living with dementia (Lockeridge \& Simpson, 2013; Quinn, Clare, Pearce, \& Van Dijkhuizen, 2008; Stokes, Combes, \& Stokes, 2014). The studies generated evidence around coping strategies (Lockeridge \& Simpson, 2013; Quinn et al., 2008), adjustment, including feelings of losing control and loss (Lockeridge \& Simpson, 2013; Quinn et al., 2008; Stokes et al., 2014), stigma (Lockeridge \& Simpson, 2013), lack of information (Stokes et al., 2014), emotional strain (Quinn et al., 2008), and isolation (Stokes et al., 2014). However, all three studies only included participants' partners only, excluding other family members. Another qualitative study including caregivers with other relationships to care recipients stated that differences were found between spousal and adult-child caregivers (Melunsky et al., 2015). However, they did not explicitly discuss these differences. Additionally, the study uses a heterogeneous group of caregivers and was not supported with demographic information, meaning it is difficult to identify differences between the subgroups. Melunsky et al. (2015) acknowledge these limitations, suggesting that research would benefit from qualitative exploration through comparison of particular groups of carers to support subgroups effectively and efficiently.

It is evident that caregiver burden is related to the subjective experience of individuals, and it is important to study the lived experience of caregivers of dementia for a more holistic understanding of the challenges caregivers deal with Shim et al. (2012). This study aims to explore the subjective lived experience of informal caregivers supporting an individual with dementia.

\section{Method}

\section{Design}

This study uses the IPA (Smith, Flowers, \& Larkin, 2009) utilizing the method of photoelicitation. Photo-elicitation is a method of data collection for which participants are given the opportunity to capture photographs and reflect on the content of these images as part of a semi-structured interview. This verbal narrative, produced in conjunction with photographs, enables an individual to provide a deep, detailed description of their own lived experience (Pilcher, Martin, \& Williams, 2015). Furthermore, using photographs within research can be a particularly powerful tool for the researcher as it can challenge participants, provide nuances, trigger memories, lead to new perspectives and explanations, and help to avoid researcher misinterpretation (Hurworth, 2004).

\section{Participants}

Six participants took part in this study (aged 53-90 years; two females, four males). Three participants were currently caregivers for a parent with dementia, and three participants were spousal ex-caregivers of which, two spouses were recently deceased and one spouse was residing in a care home. Participants' experiences of care ranged from 6 months to 15 years. Participants were contacted through various dementia service charities in the North of England. A purposive sampling strategy was used, according to IPA in order to involve individuals with a wide range of caring experiences (Smith et al., 2009). Participants were included if they were over 18 years old, and 
identified themselves as an informal caregiver supporting, or having recently supported, an individual diagnosed as having dementia. Participants were excluded if they did not have capacity to provide full, informed consent. A small sample was recruited according to IPA in order to provide detailed accounts of individual experience (Smith et al., 2009).

\section{Ethical approval}

Ethical approval was attained [by Teesside University's ethical approval board]. The confidentiality and anonymity of participants and others were of upmost importance throughout this project. Participants were fully informed of how, and when, to use the camera prior to collecting these images. Participants provided written consent to use unidentifiable photographs as part of publication.

\section{Materials}

Participants were given a $\operatorname{Kodak}^{(}{ }^{(}$disposable camera and instructed to capture photographs of anything they believed depicted their everyday experiences of being a caregiver. The camera was specifically chosen due to image quality, and all participants were given the same model. Participants were given verbal instructions of how to use the camera prior to use. Participants were given one disposable camera and were instructed to take as many photographs as they wanted to, with the only restriction being the number of photographs able to be captured on the camera $(N=27)$.

\section{Procedure}

Identified representatives of various dementia service charities were contacted via email. Charities that were interested in being involved in participant recruitment then arranged for one member of the research team to attend support groups and discuss participation in the project with service users. Interested individuals were given an information sheet and had the opportunity to ask questions. Only those wishing to continue with the study were asked to provide written informed consent. Participants were issued a disposable camera to use over a 2- to 4-week period, and as part of this, participants were given the option to take photographs of themselves and others. If participants wished to take photographs of others, they were informed that they must provide that individual with a participant information sheet and consent form.

At the end of the study period, photographs were developed, and a semi-structured interview was carried out at each participant's home (interview length between 30 and $70 \mathrm{~min}$ ) using the photographs to guide discussion. Interviews were recorded using an Olympus digital voice recorder and transcribed verbatim. Once the interview was completed, a debrief form was given to each participant reiterating the aim of the research and detailing further contact information and support.

\section{Data analysis}

Photographs were not directly analysed by the research team but were described and interpreted by the participants during the interviews. Accordingly, the photographs were used as tools within the in-depth interviews used to broaden the interview around the significance of the images for the individual (Pauwels, 2015) and are also used for 
illustration of themes. Interview transcripts were analysed using IPA (Smith et al., 2009). IPA is most appropriate when exploring individual experiences and their understanding, or sense-making, of these experiences (Smith et al., 2009). Each text was initially read line-by-line, and themes related to the subjective lived experiences of dementia caregivers were identified for each participant, then across the sample, before interpreting the coded data (Smith et al., 2009). The analysis involved the 'double hermeneutic' in that the analysts interpreted the participants' own interpretations (Smith et al., 2009). Transcripts were read multiple times through the reciprocal activity of the analysis to identify and highlight themes relating to the whole, such as the underlying meaning, and parts, to identify themes specific to the individual to retain subjectivity and understanding. Findings were discussed between the research team. Pseudonyms replaced participant names during analysis to retain anonymity.

\section{Results}

Three main themes were generated from the data: 'conceptualising the role of informal caregiver', 'support for the informal caregiver', and 'the caregivers own needs'.

\section{Conceptualising the role of informal caregiver}

Participants considered their role as caregiver in varying ways.Individuals discussed their transition to the role of caregiver and also highlighted the impact that it had on themselves as individuals. Three participants describe their role of caregiver as being a natural transition.

'I never really considered myself as a carer it just sort of slowly happened. Erm slowly crept. . .I'm officially a carer but I never thought that way it just happened' (Josef, Spouse)

'I've always been the carer, and the carer has been in my work. Erm it is a kind of a natural role' (Susan, daughter)

'It's no chore at all it's just like, it's just what I would do, it's just natural you know' (Alison, daughter)

These three participants conceptualized their changing role as progressive and natural, Susan understands her role as a caregiver for her mother as natural due to her life experience working in the care profession. She explains that in her work life, she viewed her role as caring but had never perceived her caregiving role with her mother in this way, and it simply progressed this way as the natural transition. Alison also highlights her own past lived experiences as having an impact on the role of caregiver, as her mother had taken on the caring role in the past, helping her raise her child, and because of this she feels she 'owes' her mother. Although Alison relates her responsibility to the context of an obligation, she still frames her role as natural. This suggests Alison feels, to some extent, expected to care for her mother on a personal and societal level. Whereas, for Josef as a spouse, he describes that there was no moment of realization but simply a slow and natural process. Other carers expressed a different understanding, Graham perceives his caring role as his 'duty' to care for his mother, whilst acknowledging the self-reward gained from caring. 
'It's a duty, I love my mother and you know it's a duty you do. Like coming back from Australia, I didn't want to come back, I loved it over there, but you know you have to sacrifice things. But it is rewarding in a way because you know you're doing good, you're helping somebody. And we all like to help'. (Graham, son)

By conceptualizing his caring role as his duty, Graham is able to justify the 'sacrifice' he has made to his own life. He rationalizes this sacrifice through the difference he is making to his mother's life, describing the caring role as 'rewarding'. Peter, as a spouse caregiver, describes the reward in caregiving through the satisfaction derived from his role as caregiver.

'I think I think it's very fulfilling oh yes. It's a sense of achievement you know that you're doing something that will really help someone. It just gives you a nice glow, a nice feeling yeah' (Peter, spouse)

Unlike Graham, as a spouse caregiver, Peter's understanding of his role as rewarding appears more straightforward, this may be due to the type of relationship he has with the person he cares for. The role of being an informal caregiver was viewed as rewarding and delivering a sense of achievement for some individuals, but for others, it was difficult within other aspects of their lives.

The concept of responsibility and the burdens involved with this responsibility influenced all caregivers' understandings of their role. Despite describing her role as 'natural', Susan repeatedly used tense language, such as the use of the metaphor 'juggling' her responsibilities to make sure that everyone was 'kept happy'. The pressure of the responsibility of caring for her parent was clear and evidently influenced her daily living physically but also emotionally.

'I do yeah I have to kind of soak up those negatives and its awful because they stay with me it's almost as if their emotional baggage is just dumped on you. . . you just kind of get on with it'. (Susan, daughter)

And at the same time you do feel a bit resentful, um that er nobody else offers. Or volunteers to. And then you just feel guilty if you've even thought that. *Laughs* so it's kind of a cycle of guilt, anxiety, worry cos you constantly worry about it (Susan, daughter)

Susan describes the 'cycle' of negative emotions she experiences as the main caregiver and conceptualizes the emotional strain from the caring role as 'baggage'. This conflict between her 'natural role' and the physical and emotional struggles is evident. Susan's perception of identity as a caregiver and her responsibilities, related to those around her, in being a daughter, mother, grandmother, and wife. Therefore, her understanding as a caregiver for her mother with dementia interlinked and impacted her other caring roles.

Particularly evident for those caring for a parent was the newly acquired intimate responsibilities which also exacerbated the emotional challenges of the new role, with carers having to re-conceptualize their relationship with their significant other when taking on these additional duties. Alison took a photograph of her mother's shower to illustrate the upsetting experience when she first took on the responsibility of intimate care (Figure 1).

'In the beginning it was awful to shower your mum and just quite upsetting really but embarrassing for my mum and she didn't want us to do it. But she didn't want the carers to do it' (Alison, daughter) 


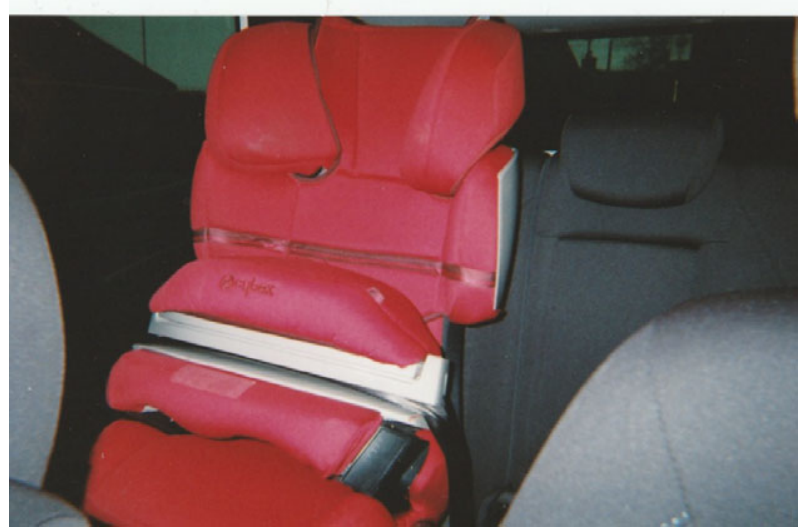

Figure I. Susan took a photograph of a children's car seat to represent her experience of multiple caring roles.

As a result of undertaking these intimate jobs, there was an internal struggle between her responsibility as a caregiver and as a daughter. This struggle is exacerbated and mirrored by Alison's mother who does not want her daughter, or formal carers, to assist with personal care. This creates an impossible situation for the caregiver whose decision to take primary responsibility has multiple emotional factors. All caregivers took photographs of bathrooms to address how assisting with personal care had a physical and emotional burden. However, those caring for a parent particularly discussed how this impacted their understanding of their caregiving role.

However, for spouse caregiver Peter he described the uptake of household chores as leading to a change in his relationship with his wife as it lessened the time they spent together and made him feel guilty (Figure 2).

'I've managed quite well really I think. It's just a part of what, you can either suppose you could get somebody in to do all the housework but I've done it all my myself really [...] sometimes you feel that you could be giving more time possibly to seeing to [my wife] erm and sitting with her, it does take away some of the time but I decided I would do the house work and carry on with it'. (Henry, Spouse)

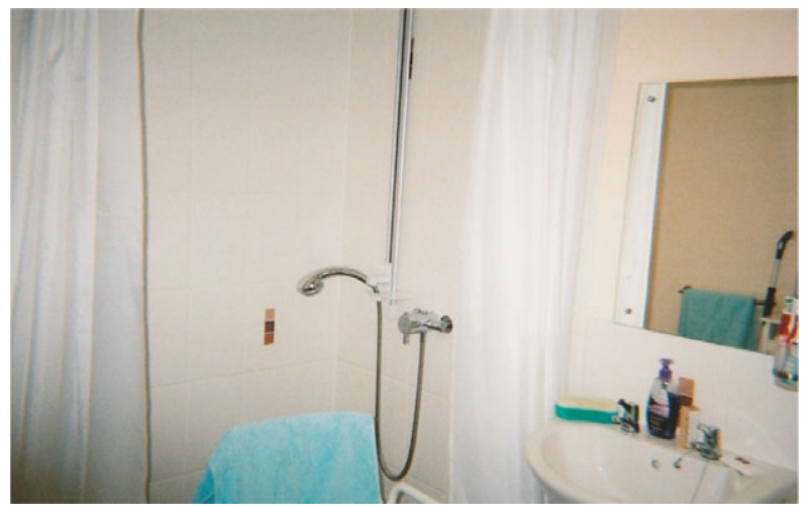

Figure 2. Alison took a photograph of the shower representing her upsetting experiences when first showering her mother. 
Henry 'managed' the housework, but felt that, in doing so, time was being taken away from being with his wife.

The transition to caregiver was difficult for individuals; however, it is evident that this transition, and the difficulties experienced, differs considerably between the type of caregiver and individual caregivers within this study. Each individual's conceptualization of their role is multifaceted, interlinked with their personal experiences, beliefs, and societal norms. This transition is complex, and based on the current and past relationship between the caregiver and loved one, the new roles acquired as caregiver, as well as other responsibilities that the caregiver has in their own life.

\section{Support arising for caregivers themselves}

The theme of support arose as an important aspect of the caring role. Often support was received indirectly through support provided for the individual living with dementia, and participants also identified the support, or lack of support, received for themselves within their role as caregiver. The way in which the participants discussed support was diverse, ranging from information received about dementia, practical aids, social support, and support for co-morbidities also experienced by their loved one. Susan described one of her photographs as the 'masses' of information available about dementia, and the support and services available to her mother (Figure 3).

However, rather than the availability of this literature increasing perceived support, Susan felt overwhelmed by the realization of her new responsibilities.

'That triggered something in me about the advice, it's almost saying well you've gotta be a carer, and this is what you've got to do. So that's a sudden kind of, again a responsibility and a change in your identity, forced on you. So it's kind of saying, it's not a choice, no, they didn't really build it into, and you didn't think to build it into your life path'. (Susan, daughter)

'The overwhelming responsibility of it that hits you when you get all of this [information]' (Susan, daughter)

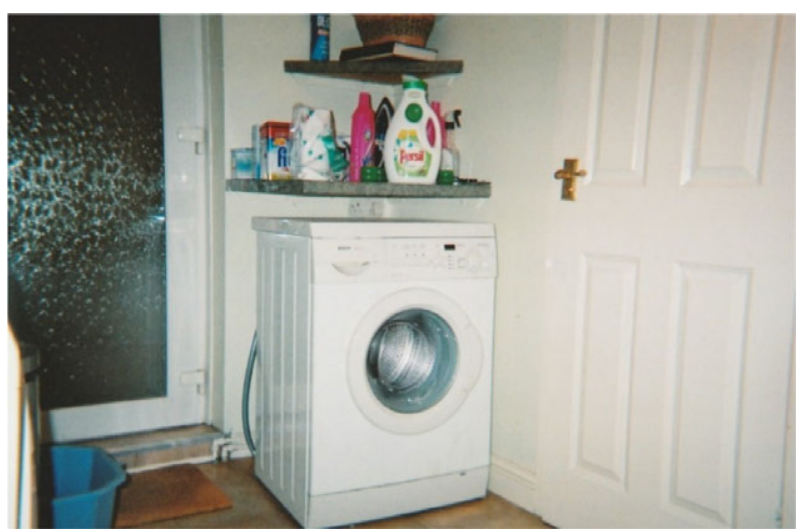

Figure 3. Peter took a photograph of the washing machine representing the responsibility of housework. 
Once more, Susan's internal conflict surfaces. Susan describes the support in relation to her change in identity and the lack of perceived control over this change. This may explain why Susan felt overwhelmed by the support that was provided as it highlighted her increased responsibilities. Another caregiver, Graham took photographs of adaptations used to increase his mother's mobility including, adapted seating, a walking frame, bathroom aids, a stair lift, and an adapted pillow (Figures 4-6).

Graham describes the many benefits of these aids and adaptations, not only for his mother, but for himself as caregiver (Figures 7 and 8).

'The better she functions the better it is for me, the easier it is for me' (Graham, son)

'We got the wheelchair because she was getting a bit slower you know she's getting older she's 89 [...] I said we'll get a wheelchair and then we can zip round quicker and she's still getting out and it gives you a life line you know, she can walk a bit and all that. . .well it gives me freedom, I can push her round' (Graham, son)

Graham describes the aids as a 'lifeline' and a 'godsend' as they allowed him more freedom and the ability to carry out the caring role more easily. Graham discusses the link between his mother's well-being and his own, by improving his mother's physical wellbeing through aids, he reduces the physical burden on himself and therefore reduces some the emotional burden caring for a parent with dementia entails.

Social support was another important aspect discussed by participants. Three individuals (Peter, Henry, and Josef) took photographs of social groups especially for individuals living with dementia, and their caregivers.

'You got chatting to other caregivers and er as well and er yeah enjoying day. . . just to talk over things really it's been a big help chatting about anything not always about your problems but sometimes yeah but er and er yes, so I found it worthwhile to go' (Josef, spouse)

'We go along for the chat and the and I get on I find that you have an affinity to people with dementia you can quite easily get on with them you know' (Peter, spouse)

Josef explains how the carer's groups act as place to socialize with others. All three spouse carers expressed the importance of the social groups for meeting others in a

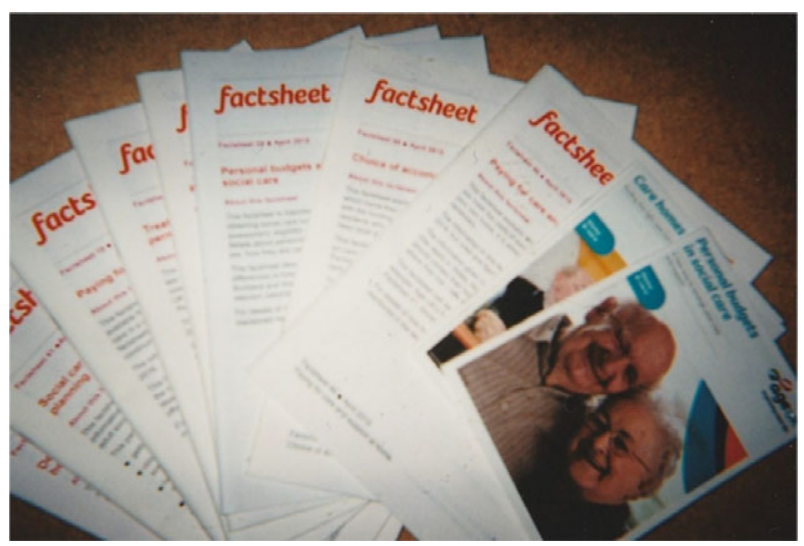

Figure 4. Susan photographed information sheets available about dementia and the services available. 

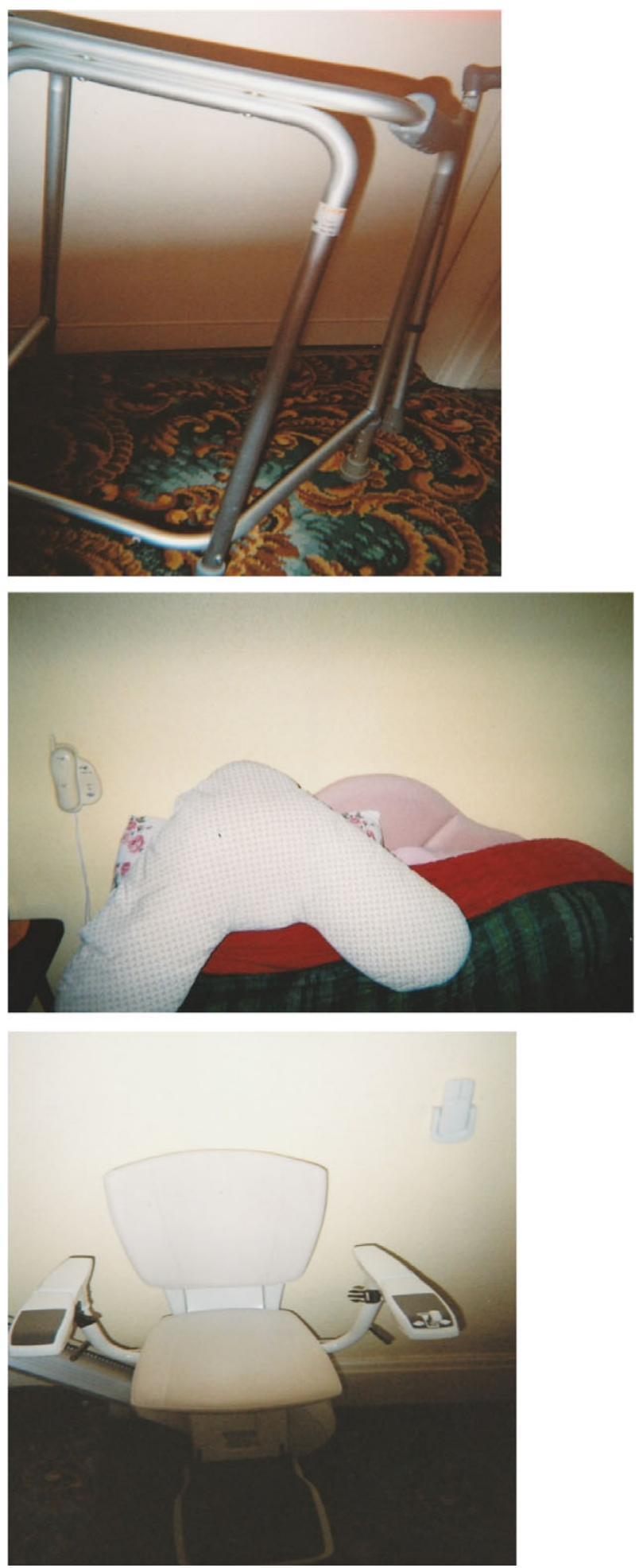

Figures 5-7. Graham took photographs of aids and adaptations used by his mother. 

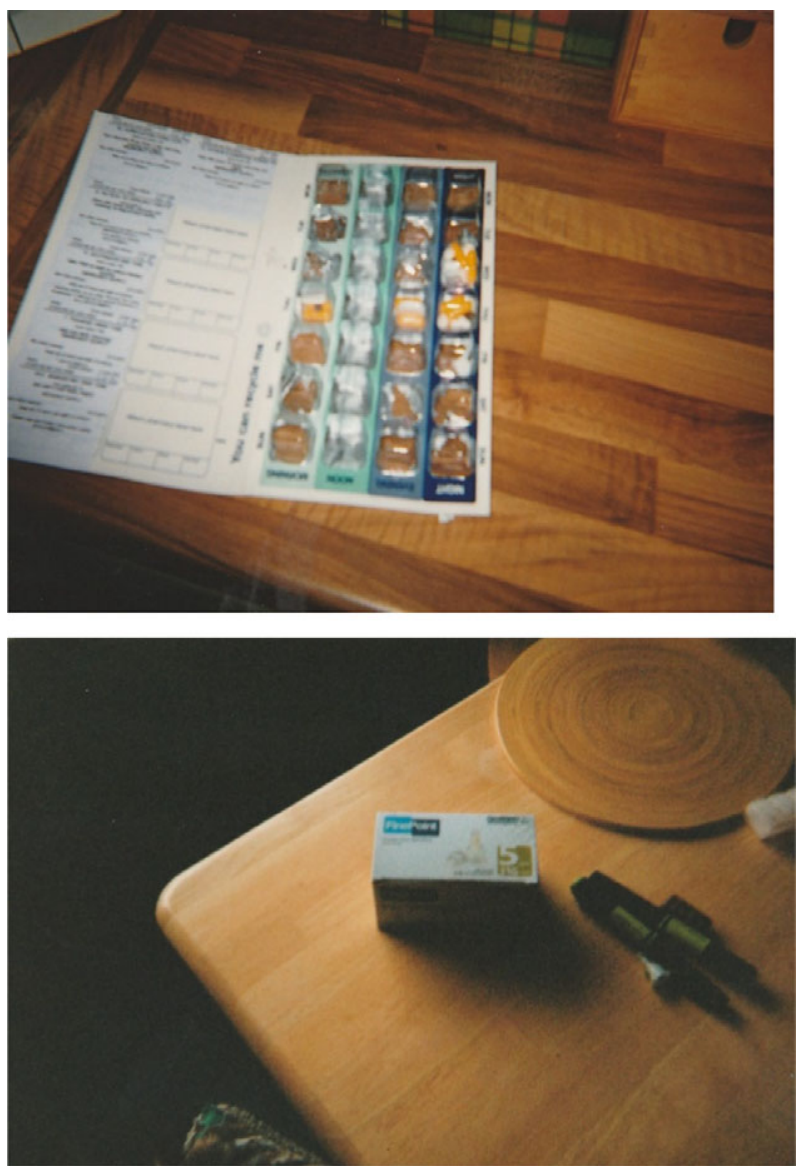

Figure 8-9. Photographs of medication for co-morbidities, taken by various participants.

similar position, discussing their experiences and providing continued emotional support. Peter also discussed the opportunity the groups gave him, allowing him to help other caregivers due to his own knowledge.

'The fact that erm I had quite a bit of knowledge of what is required in the treatment and I could understand people's problems I just felt that that was probably the sort of thing that I could help with' (Peter, spouse)

It was evident from participants that caregivers' experiences differ but having a place to meet and talk with others is an important form of support. Alison also describes how going along to the group and being around other carers provides emotional support by giving her a space to offload. However, those caring for a parent with dementia showed a different perspective on carer's support groups.

'It wasn't good at all because everybody else was the same age as their spouse who was being cared for so they could, you know kind of they enjoy it as much [... ]it was catered for a certain age it wasn't catered for I suppose what I am is what they call at the moment the sandwich generation of carers' (Susan, Daughter) 
'Like I say it gives me an opportunity to sit with other people, that was good learning from people with that experience but it's a bit scary, like, listening to some of the stories' (Alison, Daughter)

Susan explains how she felt the carers' support groups are not catered to her needs due to her age and the type of carer she is, describing herself as part of the 'sandwich generation of carers'. Whereas, Alison explains that listening to other carers' experiences is like hearing about what she might experience in the future, particularly as her mother is in the early stages of dementia. She describes hearing other carer's experiences as 'scary'; therefore, listening to other's experiences may cause Alison added emotional burden on top of caring for her mother, by highlighting the progression of the disease. Alison explained that she does not attend the carer's support group regularly; further suggesting that she does not want to be reminded of the nature of dementia and what could happen in the future. Therefore, social support was imperative to all caregivers; however, those caring for a parent emphasized the importance of social support that was not specifically from dementia support groups or other caregivers.

Although the focus of the photographs was the caregiver's lived experience of caring for an individual living with dementia, an unexpected finding emerged with regard to their lack of support with dementia, but also co-morbidities of care recipients. Various participants took photographs of pill dispensers, or medication, and described their overwhelming sense of responsibility in dealing with this. In some cases, the caregiver had become an 'expert' with their loved one's other needs, with Alison describing one of her mother's co-morbidities 'a bit like a little project of a job'.

'the blister pack for medication. . .they'd sent the blister packs in and they hadn't put the right medication in, so it's things like that that you're having to be on top of and ahead of them and just think oh I just feel you need to think all the time' (Alison, daughter)

'That's the insulin and a chocolate, well a little piece of chocolate. It's actually diabetic chocolate. . I go every day and I give her the insulin injection' (Josef, spouse)

The caregivers had responsibility for medication relating to both dementia and comorbidities. Alison describes having to be 'on top of and ahead of them', discussing various incidents where formal support had made mistakes or let her down. This suggests she has a lack of trust for formal forms of support and in order to deal with this she takes control and becomes the 'expert' in her mother's care needs. Josef discusses how he manages his wife's diabetes in relation to the routine it provides for both himself and his wife. It seemed for Josef that managing her co-morbidities helped him to continue to feel a sense of purpose and control in a situation where he has had to realize many of his care responsibilities to formal care staff. The care recipients co-morbidities were all viewed as more physical and tangible illnesses which may help to understand why carers took these photographs and how they helped carers' to feel in control of their caring roles.

\section{The caregiver's own needs}

The importance, and perceived neglect, of the caregiver's individual needs emerged from findings, with individuals feeling as though their own identity was often compromised due to their role as caregiver. Susan felt as though she had no choice in her role as informal caregiver. She described the role as being an 'a change in your identity, forced on you' and in doing so you 'lose yourself in it'. She repeatedly used language illustrating the 
challenging way in which it becomes part of the caregiver's identity, without any consideration to themselves as individuals.

'No one is really interested in what challenge it is. They are just happy that they've got somebody doing this' (Susan, daughter)

'You're just expected to do it and nothing about your own life is taken into consideration' (Susan, daughter)

'No one has ever asked me what other responsibilities that I have' (Susan, daughter)

Susan took a photograph of her research to represent her life outside of caring and what she 'wants to do', yet, she states that 'no one is interested in that' and that she 'puts it last'. When discussing her own needs, Susan often discussed not meeting others needs rather than her own but described the burden she feels in not getting time to herself. Susan discusses that no one gave her the choice of whether she would like to be a carer but instead people 'assume' and so she describes her role as 'forced' onto her. Susan consistently talks about her change in identity and role using language that clearly suggests she feels a lack of control. She highlights that others make 'assumptions' about her own responsibilities, and she feels that she often had to choose between caring for her mother, looking after her own grandchildren, or caring for her husband. Again we see Susan's perception of identity and her responsibilities, relate to those around her on a personal and societal level; daughter, mother, grandmother, wife.

The caregiver's own needs were described by participants as a time of respite where the participants were able to focus on activities for their own enjoyment and the impact this had on their own well-being and ability to care. Henry took a photograph of his wife's respite activities in which a friend cared for his wife whilst he spent time doing activities such as walking and golf (Figure 9).

'It was a bit of a release it was a release really. Because your mind is always really on her all the time so erm if you know that she's safe and alright you know you can forget it can lose it for a bit and I loved sport so and fresh air and everything and so it was that sort of help really'. (Henry, spouse)

Henry describes time of respite as a 'release' explaining how he is always thinking about his wife, whereas in these afternoons, he can 'forget' his caring role and focus on his own needs. He describes the importance of taking time for himself and its impact on his own well-being. The importance of caregiver's individual needs is further evidenced by Alison who described the importance of her sewing activities for time to herself (Figure 10).

'I've been going to my sewing class so I've been learning things new things this is a Thursday night. So again it's giving me some something for me really. That's my pleats that I've learned how to do *laughs*' (Alison, daughter)

Alison explains how going to her sewing classes gives her something for herself and her own enjoyment. However, Alison explains how allowing time for her own needs impacts upon her life and uses a photograph to highlight this (Figure 11). 


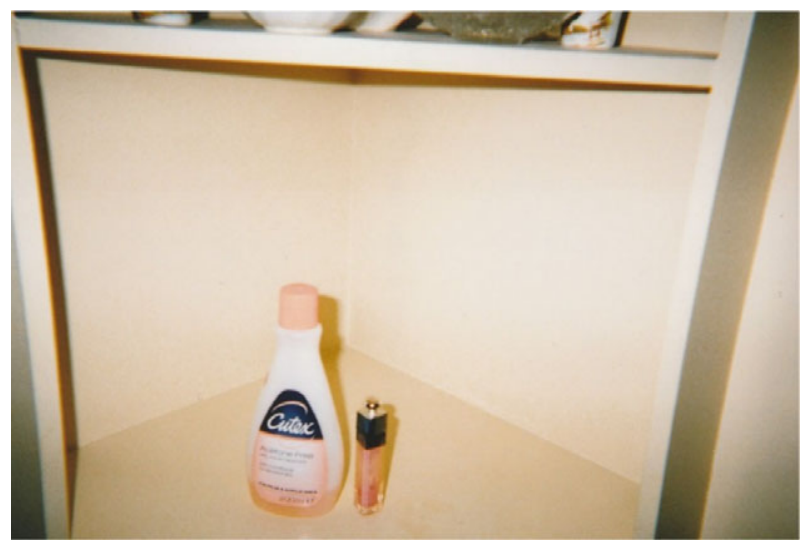

Figure 10. Henry took a photograph of his wife's nail varnish, demonstrating time that he did not need to care for her.

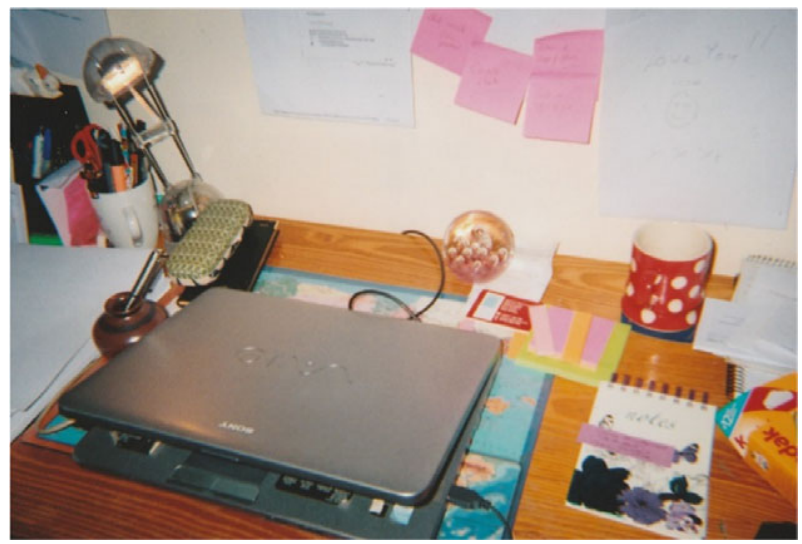

Figure II. Susan took a photograph of her work to highlight her own identity.

All carers highlighted the importance of their own needs; however, many described how they were unable to meet their own needs due to prioritizing others, specifically the care recipient's needs, before their own (Figures 12 and 13). Alison illustrates how her own needs are in conflict with the needs of her mother through a photograph of an untidy bedroom, as she is unable to provide adequate time for both, this creates an aspect of chaos in her life. Graham also describes how his own needs are interlinked with the needs of the care recipient, but in a more positive light (Figure 14).

'I: So then would the photo of the piano and stuff and also the crossword how do you think you'd feel if you didn't have that time?

P: well, well it's all work and no play then isn't it? Really, I mean I have to keep myself in tip top condition to look after mother. You know physically and mentally as well you know if I start missing out on tablets and all that then she's no good. She'd have to go in a home or we'd have to get help for me as well. So yeah, the better I am the better she is'. (Graham, son) 


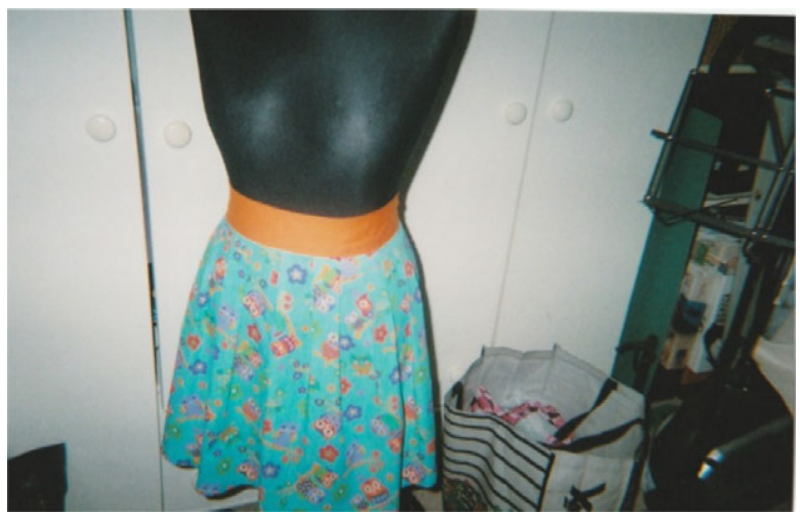

Figure 12. Alison photographed her sewing activities showing time taken for herself.

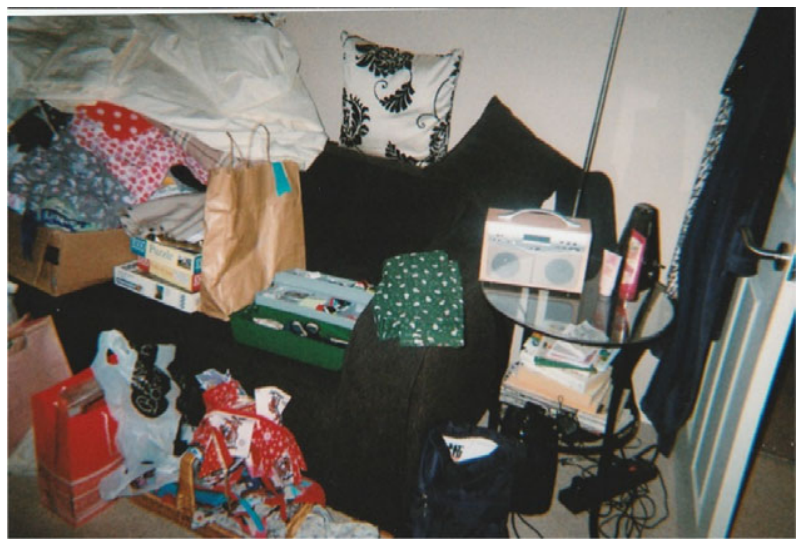

Figure I3. Alison photographed her spare bedroom full of sewing materials.

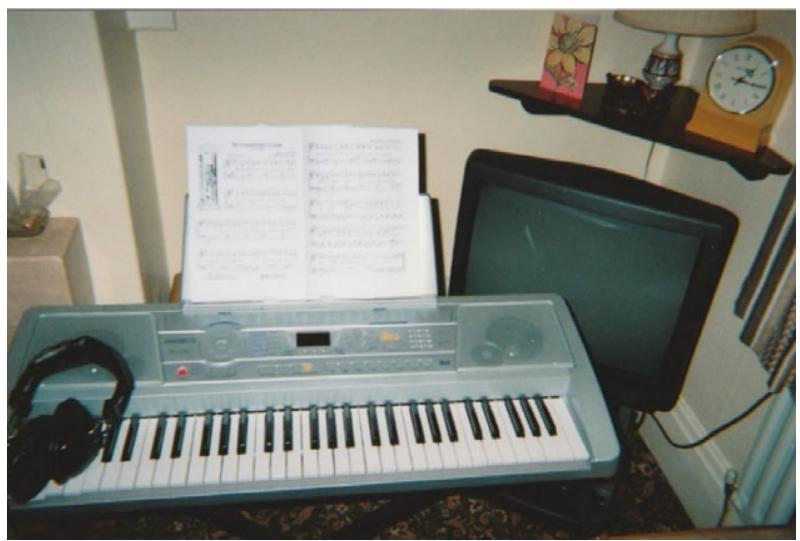

Figure 14. The caregiver's hobby of playing the piano. 
The caregiver describes how his own needs are important as it enables him to stay in 'top condition'. He explains how his own needs are intertwined with his ability to care, and explains the importance of remaining functional outside of his caring responsibilities.

Caregivers often felt that the role was thrust upon them, sometimes without consideration of other aspects of their life. Maintaining the caregivers' own identity, meeting their own needs, as well as participation in their own hobbies was clearly important for maintaining their caregiving role effectively. However, for some carers, the ability to meet their own needs and provide time for themselves was not possible.

\section{Discussion}

\section{Overall findings}

Three main themes were generated from the data: 'conceptualising the role of informal caregiver', 'support for the informal caregiver', and 'the caregivers own needs'. The complexity of the transition from family member to informal caregiver was evident with this transition evidently having both a physical and emotional impact on caregivers. The importance of the relationship between the individual and caregiver was illuminated as part of this transition and could perhaps explain some of its complexity, specifically differences between the adult child as caregiver and the spouse as caregiver. This is demonstrated in wider literature as adult-children acting as dementia caregivers have reported greater effects in terms of employment complications, role strain, and mental health problems (Ory, Hoffman, Yee, Tennstedt, \& Schulz, 1999).

It was evident that experiences of support also varied across the sample, as well as the type of support differing. Interestingly, support encompassed educational support, physical support aids, formal support, and social support. Variation in caregiving experiences is supported by previous literature which reported caregivers' perceptions of dementia as having an impact on the health of the caregivers themselves, with caregivers that report greater consequences of dementia negatively having an impact on levels of burden, physical health, and depressive symptoms (Lo Sterzo \& Orgeta 2017). Previous research has demonstrated that caregivers of individuals living with dementia feel as though they do not receive sufficient support, and experience barriers to seeking this information due to their own knowledge gaps (Peterson, Hahn, Lee, Madison, \& Atri, 2016). Furthermore, there is a lack of success of professional support for caregivers, with Brodaty, Green, and Koschera (2003) finding that informal carers generally report feelings of satisfaction and gratefulness with professional support, yet, this did not reduce their depression or caregiver burden. Within this study, social and peer support was evidently important, and wider literature identifies that support specifically tailored to help caregivers cope with their changing demands has a larger effect on caregiver well-being (Andrén \& Elmståhl, 2008). Therefore, findings highlight the importance of providing support for the caregiver rather than just to the care recipient, with caregivers stating the importance of focusing on their own individual needs in order to maintain well-being and expressed positive experiences of informal support in the form of dementia charity support groups.

The perceived neglect of the caregiver's individual needs was evident, with individuals feeling as though their own identity was often compromised due to their role as caregiver. The findings demonstrated that the caregiver's own needs were a time of respite where caregivers were able to focus on activities for their own enjoyment and the impact this had on their own well-being and ability to care. The impact of working whilst being a caregiver 
has been shown to have adverse effects on caregivers' physical, social, and emotional health (Bullock, Crawford, \& Tennstedt, 2003). Research indicates that although many family caregivers want to work and care for family members (Arksey, Kemp, Glendinning, Kotchetkova, \& Tozer, 2005), the strain from completing care responsibilities means caregivers often reduce work hours or stop working entirely (Laczko \& Sally Noden, 1993). These findings are supported by previous research highlighting that a lack of time to devote to the caregiver's own personal needs contributes to negative physical and mental health outcomes for the caregiver (Richardson, Lee, Berg-Weger, \& Grossberg, 2013). Research also suggests that a lack of time for caregiver's individual needs is related to a number of factors such as care recipients functional and cognitive dependence, lack of social support (Pinquart \& Sörensen, 2004), caregiver's working status, and resource availability (Wolfs et al., 2012). The findings accordingly lend support for the Caregiver Stress Process Model (Pearlin et al., 1990) in that a mixture of personal circumstances and characteristics, caregiver role, experiences of support, and interpretation of the caregiving experience can be seen to influence caregiver burden and the impact on carers' health and well-being.

\section{Methodological reflections}

The use of photo-elicitation as a method of qualitative investigation was a key strength of the current study. A main characteristic of this approach is analysing how participants ascribe meaning and values to these images and allows exploration of a phenomenon within a social context (Ruby, 1995). It is suggested that additional methods to interviews in qualitative inquiry allow for richer more nuanced data (Black, 1994). Furthermore, photo-elicitation can overcome some of the problems faced with qualitative interviewing in that the understanding of both participant and researcher is grounded in the photograph (Harper, 2002). However, previous qualitative research into the lived experiences of caregivers of dementia has only utilized interviews. Photo-elicitation has been used as an innovative method to capture lived experiences in other clinical and community settings with different populations, for example, experiences of recovery in a hospital setting (Radley \& Taylor, 2003), men's' experiences of living with prostate cancer (Oliffe \& Bottorff, 2007), and women's experiences of chemotherapy (Frith \& Harcourt, 2007). To the researchers' knowledge, the current study is the first of its kind to utilize photo-elicitation when investigating the experiences of caregivers of dementia; thus, providing a unique insight into these experiences.

The photographs provided an innovative way of capturing the lived experiences of formal dementia caregivers and allowed the interview data to be grounded in their daily living, centring around their own lived experiences. It was clear that the photographs had multiple meanings for carers which enabled them to discuss the physical and tangible aspects of their lives, often not discussed within an interview setting. This then allowed for further prompting into their emotional reactions and responses with the photographs, transporting them to how they felt when the photograph was taken. Often caregivers used photographs as metaphors for their current situations that without the interactive use of cameras, they would likely not be able to put into words and may have been misinterpreted by the researchers. The photographs facilitated carers to place their experience within a context, providing subjectivity to a further level. Therese snapshots into people's everyday lived experiences and descriptions that could not be captured by photographs or interviews alone and make the carers' the experts in their own experiences. 
When participants discussed the experience of using the camera, the response was positive, and participants anecdotally felt that it was a good way of capturing and remembering their thoughts.

This study specifically utilized photo-elicitation, as opposed to more participatory photography methods such as photovoice, as the interview was led by the researcher whilst considering and being led by the research aims, rather than being truly participant led. Within more participatory approaches, the verbal narrative, produced in conjunction with photographs, enables an individual to provide a deep, detailed description of their own lived experience (Pilcher et al., 2015). Using photo-elicitation interviews still allows individuals to express themselves within the research (Harper, 2002; Pauwels, 2015).

A key limitation of the research related to timescale and demographics, with all participants recruited from a small area in the North East of England. This has implications for the transferability of findings due to a lack of diversity between participants, as well as similarity of provision by the local authority and local third-sector services.

\section{Future research and practice implications}

Future research would benefit from recruiting a wider, diverse sample, spanning multiple local authority sites. Furthermore, the differences identified between spousal caregivers and adult-child caregivers within themes suggest that future research should look into the differences in the caregiving experience between spousal and adult-children caregivers of people living with dementia.

\section{Conclusions}

Through qualitative investigation, the study found three key areas of dementia caregiving that related to the lived experience. The themes highlight aspects of caregiving that is specific to caregiver's experiences. The caregiver's own needs were found to be important for their own well-being and continuation of care, whilst positive experiences of informal assistance emphasize the value of carer focused support. Finally, a notable difference was found between experiences of spousal caregivers and adult-child carers, particularly in their conceptualization of the role. Further exploration of these differences is essential for understanding carers of dementia in the United Kingdom and providing appropriate services. Findings demonstrate the importance of implementing countrywide emotional support for caregivers focusing on their individual needs and employing suitable coping strategies. In conclusion, by understanding the day-to-day experiences, findings have illuminated the lived experience of carers of dementia in the United Kingdom, adding to the small body of existing literature and highlighting important issues for both future intervention programmes and research.

\section{Conflict of interest}

All authors declare no conflict of interest.

\section{References}

Alzheimer's Disease International. (2014). World Alzheimer Report 2014 Dementia and risk reduction: An analysis of protective and modifiable factors. London, UK. 
Alzheimer's Society (2014). Dementia UK update. London, UK: Alzeihmer's Society.

Andrén, S., \& Elmståhl, S. (2008). The relationship between caregiver burden, caregivers' perceived health and their sense of coherence in caring for elders with dementia. Journal of Clinical Nursing, 17(6), 790-799. https://doi.org/10.1111/j.1365-2702.2007.02066.x

Arksey, H., Kemp, P., Glendinning, C., Kotchetkova, I., \& Tozer, R. (2005). Carers' aspirations and decisions around work and retirement (Vol. 290). Leeds, UK: Corporate Document Services.

Ayres, L. (2000). Narratives of family caregiving: Four story types. Research in Nursing \& Health, 23 (5), 359-371. https://doi.org/10.1002/(ISSN)1098-240X

Black, N. (1994). Why we need qualitative research. Journal of Epidemiology and Community Health, 48(5), 425. https://doi.org/10.1136/jech.48.5.425-a

Bremer, P., Cabrera, E., Leino-Kilpi, H., Lethin, C., Saks, K., ... Sutcliffe, C., RightTimePlaceCare Consortium. (2015). Informal dementia care: Consequences for caregivers' health and health care use in 8 European countries. Health Policy, 119(11), 1459-1471. https://doi.org/10.1016/ j.healthpol.2015.09.014

Brodaty, H., Green, A., \& Koschera, A. (2003). Meta-analysis of psychosocial interventions for caregivers of people with dementia. Journal of the American Geriatrics Society, 51(5), 657664. https://doi.org/10.1034/j.1600-0579.2003.00210.x

Bullock, K., Crawford, S. L., \& Tennstedt, S. L. (2003). Employment and caregiving: Exploration of African American caregivers. Social Work, 48(2), 150-162. https://doi.org/10.1093/sw/48.2. 150

Etters, L., Goodall, D., \& Harrison, B. E. (2008). Caregiver burden among dementia patient caregivers: A review of the literature. Journal of the American Association of Nurse Practitioners, 20(8), 423-428. https://doi.org/10.1111/j.1745-7599.2008.00342.x

Frith, H., \& Harcourt, D. (2007). Using photographs to capture women's experiences of chemotherapy: Reflecting on the method. Qualitative Health Research, 17(10), 1340-1350. https://doi.org/10.1177/1049732307308949

Harper, D. (2002). Talking about pictures: A case for photo elicitation. Visual Studies, 17(1), 13-26. https://doi.org/10.1080/14725860220137345

Hurworth, R. (2004). Photo-interviewing. Qualitative Research Journal, 4(1), 73.

Ivey, S. L., Laditka, S. B., Price, A. E., Tseng, W., Beard, R. L., Liu, R., . . Logsdon, R. G. (2013). Experiences and concerns of family caregivers providing support to people with dementia: A cross-cultural perspective. Dementia, 12(6), 806-820. https://doi.org/10.1177\%2F1471301212446872

Joling, K. J., van Hout, H. P., Schellevis, F. G., van der Horst, H. E., Scheltens, P., Knol, D. L., \& van Marwijk, H. W. (2010). Incidence of depression and anxiety in the spouses of patients with dementia: A naturalistic cohort study of recorded morbidity with a 6-year follow-up. The American Journal of Geriatric Psychiatry, 18(2), 146-153. https://doi.org/10.1097/JGP.0b 013e3181bf9fof

Kasuya, R. T., Polgar-Bailey, P., \& Takeuchi, R. (2000). Caregiver burden and burnout a guide for primary care physicians. Postgraduate Medicine, 108(7), 119.

Kim, H., Chang, M., Rose, K., \& Kim, S. (2012). Predictors of caregiver burden in caregivers of individuals with dementia. Journal of Advanced Nursing, 68(4), 846-855. https://doi.org/10. $1111 / \mathrm{j} .1365-2648.2011 .05787 . \mathrm{x}$

Laczko, F., \& Sally Noden, B. A. (1993). Combining paid work with eldercare: The implications for social policy. Health \& Social Care in the Community, 1(2), 81-89.

Lockeridge, S., \& Simpson, J. (2013). The experience of caring for a partner with young onset dementia: How younger carers cope. Dementia, 12(5), 635-651. https://doi.org/10.1177/ 1471301212440873

Lo Sterzo, E., \& Orgeta, V. (2017). Illness representation and sense of coherence in dementia caregiving. Journal of health psychology, 22(6), 722-732.

Mahoney, R., Regan, C., Katona, C., \& Livingston, G. (2005). Anxiety and depression in family caregivers of people with Alzheimer disease: The LASER-AD study. The American Journal of Geriatric Psychiatry, 13(9), 795-801. https://doi.org/10.1097/00019442-200509000-00008 
Melunsky, N., Crellin, N., Dudzinski, E., Orrell, M., Wenborn, J., Poland, F., ... Charlesworth, G. (2015). The experience of family carers attending a joint reminiscence group with people with dementia: A thematic analysis. Dementia, 14(6), 842-859. https://doi.org/10.1177/ 1471301213516332

Oliffe, J. L., \& Bottorff, J. L. (2007). Further than the eye can see? Photo elicitation and research with men. Qualitative Health Research, 17(6), 850-858. https://doi.org/10.1177/1049732306298 756

Ory, M. G., Hoffman, III, R. R., Yee, J. L., Tennstedt, S., \& Schulz, R. (1999). Prevalence and impact of caregiving: A detailed comparison between dementia and nondementia caregivers. The Gerontologist, 39(2), 177-186. https://doi.org/10.1093/geront/39.2.177

Pauwels, L. (2015). 'Participatory'visual research revisited: A critical-constructive assessment of epistemological, methodological and social activist tenets. Ethnography, 16(1), 95-117. https://doi.org/10.1177/1466138113505023

Pearlin, L. I., Mullan, J. T., Semple, S. J., \& Skaff, M. M. (1990). Caregiving and the stress process: An overview of concepts and their measures. The Gerontologist, 30(5), 583-594. https://doi.org/ $10.1093 /$ geront/30.5.583

Peterson, K., Hahn, H., Lee, A. J., Madison, C. A., \& Atri, A. (2016). In the information age, do dementia caregivers get the information they need? Semi-structured interviews to determine informal caregivers' education needs, barriers, and preferences. BMC Geriatrics, 16(1), 164. https://doi.org/10.1186/s12877-016-0338-7

Pilcher, K., Martin, W., \& Williams, V. (2015). Issues of collaboration, representation, meaning and emotions: Utilising participant-led visual diaries to capture the everyday lives of people in mid to later life. International Journal of Social Research Methodology, 19(6), 477-692. https://doi. org/10.1080/13645579.2015.1086199

Pinquart, M., \& Sörensen, S. (2004). Associations of caregiver stressors and uplifts with subjective well-being and depressive mood: A meta-analytic comparison. Aging \& Mental Health, 8(5), 438-449. https://doi.org/10.1080/13607860410001725036

Quinn, C., Clare, L., Pearce, A., \& Van Dijkhuizen, M. (2008). The experience of providing care in the early stages of dementia: An interpretative phenomenological analysis. Aging and Mental Health, 12(6), 769-778. https://doi.org/10.1080/13607860802380623

Radley, A., \& Taylor, D. (2003). Images of recovery: A photo-elicitation study on the hospital ward. Qualitative Health Research, 13(1), 77-99. https://doi.org/10.1177/1049732302239412

Richardson, T. J., Lee, S. J., Berg-Weger, M., \& Grossberg, G. T. (2013). Caregiver health: Health of caregivers of Alzheimer's and other dementia patients. Current psychiatry reports, 15(7), 367. https://doi.org/10.1007/s11920-013-0367-2

Ruby, J. (1995). Secure the shadow: Death and photography in America. Cambridge, MA: MIT Press.

Schulz, R., Boerner, K., Shear, K., Zhang, S., \& Gitlin, L. N. (2006). Predictors of complicated grief among dementia caregivers: A prospective study of bereavement. The American Journal of Geriatric Psychiatry, 14(8), 650-658. https://doi.org/10.1097/01.JGP.0000203178.44894.db

Shim, B., Barroso, J., \& Davis, L. L. (2012). A comparative qualitative analysis of stories of spousal caregivers of people with dementia: Negative, ambivalent, and positive experiences. International Journal of Nursing Studies, 49(2), 220-229. https://doi.org/10.1016/j. ijnurstu.2011.09.003

Simpson, C. (2010). Case studies of Hispanic caregivers of persons with dementia: Reconciliation of self. Journal of Transcultural Nursing, 21(2), 167-174. https://doi.org/10.1177\% 2F1043659609357630

Simpson, C., \& Carter, P. A. (2010). Pilot study of a brief behavioral sleep intervention for caregivers of individuals with dementia. Research in Gerontological Nursing, 3(1), 19-29. https://doi.org/ 10.3928/19404921-20090731-02

Smith, J., Flowers, P., \& Larkin, M. (2009). Interpretative phenomenological analysis: Theory, method and research. London, UK: Sage. 
Stokes, L. A., Combes, H., \& Stokes, G. (2014). Understanding the dementia diagnosis: The impact on the caregiving experience. Dementia, 13(1), 59-78. https://doi.org/10.1177/1471301212 447157

Wolfs, C. A., Kessels, A., Severens, J. L., Brouwer, W., de Vugt, M. E., Verhey, F. R., \& Dirksen, C. D. (2012). Predictive factors for the objective burden of informal care in people with dementia: A systematic review. Alzheimer Disease \& Associated Disorders, 26(3), 197-204. https://doi.org/ 10.1097/WAD.0b013e31823a6108

World Health Organisation. (2017, May). Dementia. Retrieved from http://www.who.int/mediace ntre/factsheets/fs362/en/

Received I4 February 2018; revised version received 28 August 2018 